\title{
Combination Of Biochemical And Hyperspectral Remote Sensing Methods For Detection Of Heavy Metal Pollutions In Eucalyptus Leaves (Case Study: The City Of Bam)
}

\author{
R. Khalilia ${ }^{\mathrm{a}}$ S. Anvari ${ }^{\mathrm{b}}$, M. Honarmand ${ }^{\mathrm{c}}$ \\ ${ }^{a}$ M.Sc. student of geological remote sensing, Graduate University of Advanced Technology, Kerman, Iran \\ rezakhalili6565@gmail.com
}

${ }^{\mathrm{b}}$ Assistant Prof., Department of Ecology, Institute of Science and High Technology and Environmental Science, Graduate University of Advanced Technology, Kerman, Iran. anvari.t@gmail.com

\footnotetext{
${ }^{c}$ Assistant Prof., Department of Ecology, Institute of Science and High Technology and Environmental Science, Graduate University of Advanced Technology, Kerman, Iran. m.honarmand@kgut.ac.ir
}

KEY WORDS: Biochemical analysis, hyperspectral remote sensing, As, Pb, Eucalyptus, Bam city.

\begin{abstract}
:
Environmental pollution may be caused due to mines and mineral deposits. The accumulation of the associated heavy metals in soil and especially at the root zone of plants would result in plant contamination. This paper aims to detect the dominant heavy metals in Eucalyptus leaves using both biochemical and hyperspectral techniques for northern part of Bam in Iran. In this regards, using biochemical approach, some Eucalyptus leaf samples were collected, and their laboratory data containing the concentration of heavy metals were measured by Graphite Furnace Atomic Absorption Spectrometry (GF-AAS). Using ASD FieldSpec3 Pro spectrometer (Analytical Spectral Devices) also, the spectral profile of leaf samples was measured and compared with healthy ones namely control samples. Finally, using supervised classification methods, the spatial distribution of heavy metals was determined by combination of biochemical results, spectral measurements of samples and hyperspectral images of EO-1 satellite. Results showed that Eucalyptus trees accumulates the heavy metals of $\mathrm{As}$ and $\mathrm{Pb}$ with the average concentrations equalling 9.98 and $14.31 \mathrm{ppb}$ while compared with the relevant control samples equalling 2.32 and $8.98 \mathrm{ppb}$, respectively. Combination of biochemical and hyperspectral data analysis also proved by increasing heavy metals concentrations in all samples, their spectral profiles for the visible and near infrared regions will be changed in comparison with those obtained from the control sample.
\end{abstract}

\section{NTRODUCTION}

Accumulation of heavy metals in the soil often causes the environmental pollutions and their respective effects may be appeared in the plants (http://www.epa.gov). Therefore these plants can be good evident for identifying heavy metal contaminations in a region (Pugh et al., 2002). The resulted contaminations also might be incorporated into food chains and ecosystems cycle. So the investigation of such these contaminated plants is essential for sustainable developments of ecosystems and human health (Liu et al., 2010).

Traditionally heavy metal concentrations in plants were approximated by field sampling and extensive laboratory tests (e.g. Pugh et al., 2002; Conesa et al., 2006). However for intensive plant sampling, this method may be costly and timeconsuming. The resulted information also could not describe the dynamics of heavy metal concentrations throughout the large areas (Liu et al., 2010).

Nowadays the advanced remote sensing technologies, especially hyperspectral imaging system, have been widely employed to obtain the earth information in a timely and cost effective manner (Darmavan, 2006). Having developed the hyperspectral remote sensing techniques, they were also used to assess biochemical properties of plants (Mutanga and Skidmore, 2004b; Mutanga et al., 2007). However, a review of the literature shows that remote sensing images or hyperspectral data have rarely been applied for retrieving heavy metal concentrations in plants. For example, Rosso et al. (2005) investigated the possibility of detecting a spectrally specific response in plant of Salicornia Virginica induced by a particular metal. Their findings demonstrated that the reflectance was sensitive to early stress levels only for cadmium and the lightweight petroleum. Surveying the heavy metal contamination and the biogeochemistry responses of vegetation Rhus chinensis, Li et al. (2008) found that leaf reflectance have significantly correlation with $\mathrm{Cu}$ concentration in leaves. Shakya et al. (2008) showed that the excessive heavy metals in plant affect its chlorophyll content. This issue could be continuously monitored by hyperspectral images or fieldmeasured hyperspectral data (Blackburn, 1998). During recent years, hyperspectral imaging system has been successfully used 
to identify geological features (Kratt, Calvin and Coolbaugh, 2004; Kruse et al., 2003). These Hyperspectral data have also been an alternative to conventional ground-based methods to detect plant stress and play a valuable role in providing timespecific and time-critical information for precision farming (Liu et al., 2011). Furthermore, with the launch of hyperspectral sensors such as Hyperion on board Earth Observation One (EO1) platform, such this information could be extracted with a higher degree of accuracy. This is due to the Hyperion's capability of producing 242 contiguous spectral resolution elements from 0.356 to $2.577 \mu \mathrm{m}$ with $10 \mathrm{~nm}$ band interval. In addition, the 30-meter spatial resolution provides another advantage since the feature of interest could be mapped in more detail. The Hyperion sensors are spatially able to collects image for a narrow area for about $7.7 \mathrm{~km}$ in the across track direction (width) and $42 \mathrm{~km}$ in the long track direction (Stephen et al., 2003, Darmavan, 2006).

With respect to the mentioned studies, the problems caused by environmental pollutions and the necessity of using more efficient methods for data acquisition, the main objective of this paper is to detect the dominant heavy metals in Eucalyptus leaves using both biochemical and hyperspectral techniques. In this regards, using biochemical approach, the concentration of heavy metals were measured by Graphite Furnace Atomic Absorption Spectrometry (GF-AAS). Using ASD FieldSpec3 Pro spectrometer also, the spectral signature of leaf samples was measured and compared with control samples i.e. unpolluted ones. Finally, by combination of laboratory analysis, spectrometry of samples, hyperspectral images and implementing supervised classification methods, the spatial distribution of heavy metals in the region was determined. To evaluate the proposed methodology, the northern area of Bam city in Kerman, was chosen as the case study.

\section{MATERIALS AND METHODS}

\subsection{Case Study}

The city of Bam is located in south-eastern of Kerman province in Iran (Figure 1). According to the geological map of Bam City, published by Geological Survey of Iran (GSI), the main porphyry deposits of this region is located in the northern part of Bam which is hosted by quaternary alluvial deposits. Moreover, only the northern and north-eastern parts of this region has been covered by Eocene formations and consisted of some heavy metals like lead $(\mathrm{Pb})$, Arsenic (As), barite, gold $\mathrm{Au}$ ) and copper $(\mathrm{Cu})$. The Eucalyptus trees are known to be the main plant species in the region and may translocate some heavy metals like $\mathrm{Au}$ from mineral deposits (Lintern et al., 2013). Figure 1, shows the location of the study area and the satellite image correspond to it.

\subsection{Spectroscopic data}

The fieldwork of current study has been carried out throughout the 8 Eucalyptus sampling sites in northern part of Bam City, as the polluted sites. At each sampling site, around 3 Eucalyptus leaves were collected from the upper parts of plants and labelled as the polluted samples. Moreover, some Eucalyptus leaves from Kerman City were taken as an unpolluted sample and labelled control sample. Having taken all leaf samples to the laboratory, the ASD (Analytical Spectral Devices) FieldSpec ${ }^{\circledR}$ Pro spectrometer was employed to measure the spectral profile of leaf samples. Afterwards, the initial pre-processing of spectral profiles was conducted using ViewSpecPro software to obtain the reflectance spectra which were saved into the spectral library. These extracted spectra were finally used to be compared with the biochemical results of the laboratory analysis.

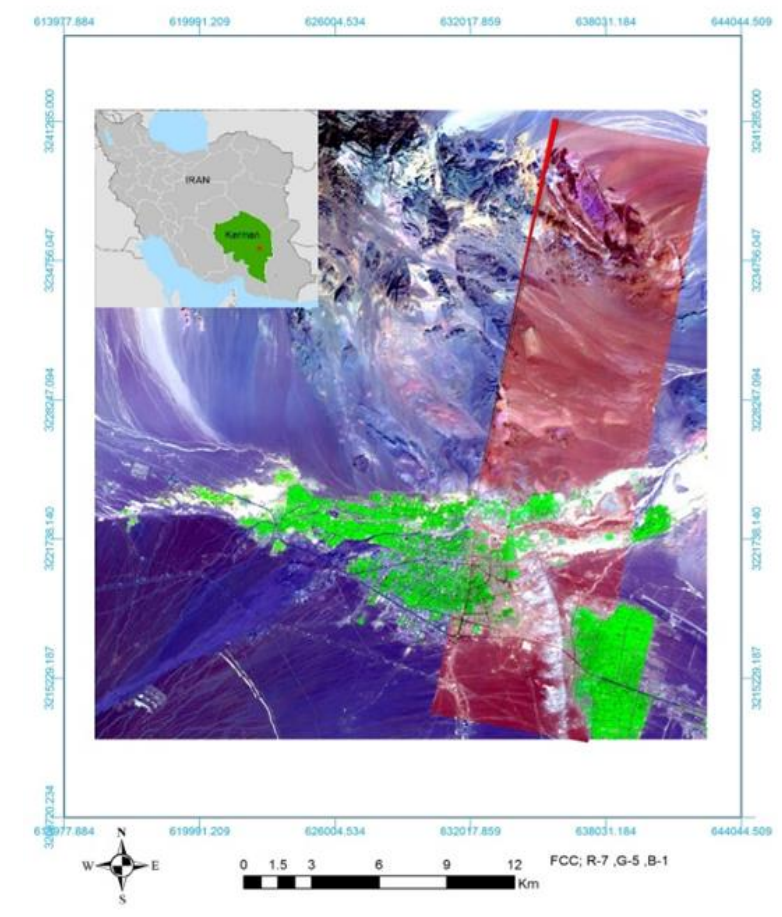

Figure 1. Location of study area and its satellite image

\subsection{Biochemical Data based on the Laboratory analysis}

Biochemical data containing the concentration of heavy metals were determined by Graphite Furnace Atomic Absorption Spectrometry (GF-AAS). For this aim, all Eucalyptus samples were placed into an oven at $70{ }^{\circ} \mathrm{C}$ for 72 hours to be completely dried. Samples then were digested with $90{ }^{\circ} \mathrm{C}$ aqua regia ( $\mathrm{HNO} 3: \mathrm{HCl}$ ratio $1: 3$ ). Heavy metal concentrations were finally determined by graphite furnace atomic absorption spectrometry (GFAAS).

\subsection{Hyperspectral Data}

Six Hyperion images for period of 2002-2004 years were initially used in this research. Among of them therefore three images with minimal noise and clouds were selected. It's worth mentioning that Hyperion data acquired in this study comes as Level 1T (L1T) products. The radiometric and systematic geometric corrections incorporating ground control points have been applied while employing a 90-meter Digital Elevation Model (DEM) for topographic accuracy (https://lta.cr.usgs.gov/EO1.html). Although the Hyperion sensor was designed to record 242 bands, some bands are not appropriate for data analysis process. So, 198 out of 242 bands would be used as input for image processing and identification of target materials. 


\subsection{Hyperspectral data analysis}

Although there is no strict procedures to extract information from remotely sensed hyperspectral image data, the following stages which have been listed in figure 2, are known to be appropriate for preprocessing and processing of data (Kruse, 2003). For making such these corrections in this paper we used the ENVI ${ }^{1}$ software in both preprocessing and processing stages.

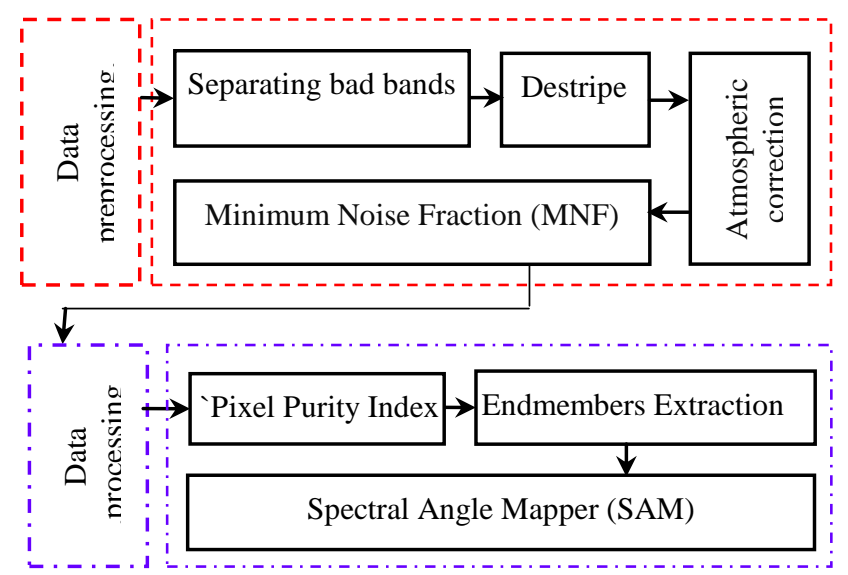

Figure. 2 Different stages for preprocessing and processing of Hyperion data

\subsubsection{Data Pre-processing}

The pre-processing procedures composed of radiometric and geometric corrections to remove the effects of sensor and environmental factor (Darmavan, 2006). So the destriping of data images, atmospheric corrections by FLAASH technique and minimizing noise of Hyperion images are all radiometric corrections which carried out in this paper.

\section{a) Separating bad bands}

While using the Hyperion images, the zeroed bands and strong water vapor bands are supposed to be "bad bands" and will be ignored in further processing. To treat these bands in an image one method, which is employed in this study, is to exclude them permanently by creating an image subset containing only the good bands (http://www.exelisvis.com).

\section{b) Destripe}

In order to address sensor specific issue, the destriping of data images is currently applied. In pushbroom scanner such as Hyperion the difference in gain and offsets and temperature effect would likely caused striping in the images (Darmavan, 2006). When destriping the data, ENVI calculates the mean of every nth line and normalizes each line to its respective mean Research Systems Inc. (2005).

\section{c) Atmospheric correction}

The presence of water vapor and carbon dioxide molecules, aerosols etc. in the atmosphere creates atmosphere dynamic processes in the form of radiation scattering and absorption. In order to acquire the actual surface reflectance and minimize the effects of atmosphere, the atmospheric correction is needed (Darmawan, 2006). To achieve this goal the FLAASH ${ }^{2}$ technique was employed in this paper.

\footnotetext{
${ }^{1}$ Environment for Visualizing Images: ENVI

2 Fast Line-of-sight Atmospheric Analysis of Spectral Hypercubes
}

\section{d) Mimizing Noise and Dimensionality of Data}

Since the extraction of more detail information in hyperspectral imaging system is carried out through the record of narrow bands, most hyperspectral data would have redundant information which likely increases the amount of time and computing resources needed to process the data. So the Minimum Noise Fraction (MNF) transformation, available in ENVI software, was employed to reduce the dimensionality of data and minimize their noise.

\subsubsection{Data Processing}

To process the Hyperion images in this section some techniques as following were employed:

\section{a) Determination of pure pixels}

Pixel purity index (PPI) is commonly used to find the extreme pixels or spectrally pure pixel (ENVI help). According to description of Research Systems Inc (2005) PPI is computed by repeatedly projecting $\mathrm{n}$-dimensional scatterplot into a random 2D space, and recording each extreme pixel found in the iteration. The record of each pixel is then used to create a PPI image where the digital number (DN) of the pixels corresponds to the number of times where that pixel recorded as extreme pixel (Research Systems Inc, 2005).

\section{b) Endmembers Extraction $\backslash$}

Endmembers are spectrally pure unique materials that occur in a scene. Having indicated the image's purest pixels, ENVI provides several methods to identify the endmembers. The most powerful one that used in current study is n-Dimensional Visualizer method which interactively selects the endmembers in $\mathrm{n}$ space. However, this method is subject to the analyst experience and knowledge, so careful action need to be taken to minimize the bias from occurring.

c) Supervised classification using Spectral Angel Mapper Spectral Angle Mapper (SAM) algorithm is based on the measurement of the spectral similarity between two spectra. The spectral similarity can be obtained by considering each spectrum as a vector in $n$-dimensional space, where $n$ is the number of bands. The SAM algorithm determines the spectral similarity between two spectra by calculating the angle between the two spectra (Rashmi et al., 2014)

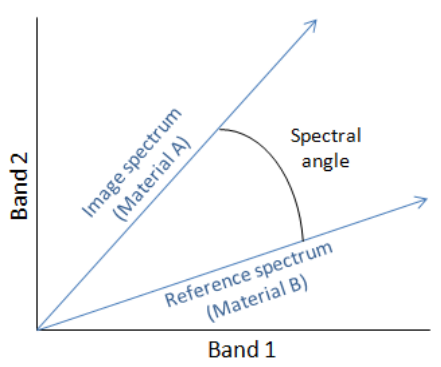

Figure 3. Spectral angle between image and reference spectra in SAM algorithm (Rashmi et al., 2014)

\section{RESULTS AND DISCUSSIONS}

This section presents the results of different stages of current study including laboratory and spectroscopic analysis as well as Hyperspectral processes. It also discusses the Hyperspectral findings based on the supporting theory and compares them with those resulted from laboratory analysis. 


\subsection{Spectroscopic Results}

The spectral measurements of this study were taken using an ASD spectrometer. This spectrometer was operated in the 350 $2500 \mathrm{~nm}$ spectral regions with the sampling interval of $1 \mathrm{~nm}$. The reflectance spectra of leaf samples were measured through calibration with a standardized white spectrum panel. Figure 4 shows some spectral profiles of Eucalyptus leaves for both contaminated and control samples.

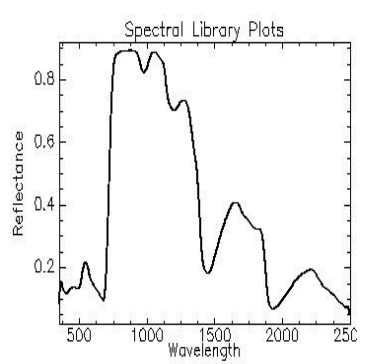

a) Control sample

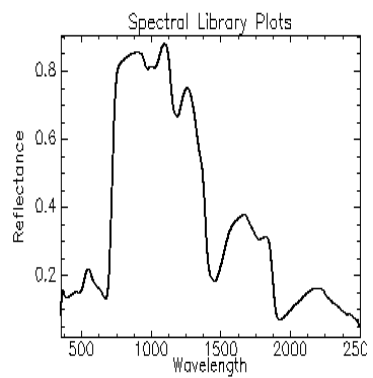

c) Sample 5

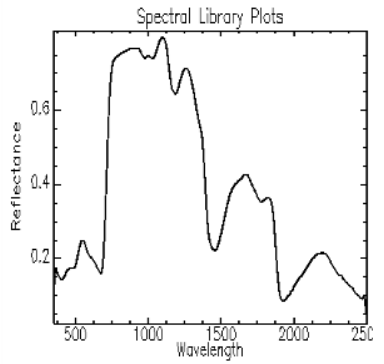

b) Sample 1

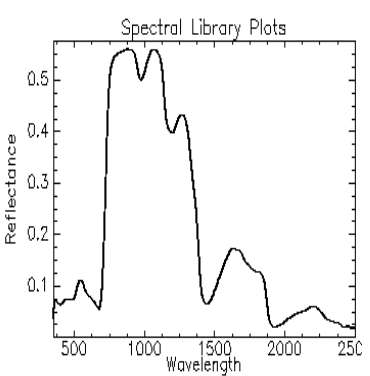

d) Sample 8
Figure 4. The spectral profile of Eucalyptus leaves for control and polluted samples $1,5,8$

As shown in figure 4, there is nearly a bit difference in the Red Edge Position (REP) for all samples. Comparing with the control sample, some samples like 1 and 5 have different values of reflectance in the range of 940-1120 nm. In the other word, a weak reflectance peak is observed around this range, namely in near infrared region.

\subsection{Biochemical Results Based on Laboratory Analysis}

Using the GF-AAS device, the concentration of some heavy metals like $\mathrm{As}, \mathrm{Pb}$ and $\mathrm{Cu}$ was determined in the laboratory. According to figure 5, the respective results of biochemical analysis demonstrates that the average concentrations of As and $\mathrm{Pb}$ for all samples is significantly higher than control ones. The relevant average of these heavy metals concentrations for all 8 samples is equal to 9.98 and $14.31 \mathrm{ppb}$ while compared with the control samples equalling 2.32 and $8.98 \mathrm{ppb}$, respectively. So one can say the Eucalyptus trees are good accumulators for As and $\mathrm{Pb}$ heavy metals. Laboratory analysis also confirmed that there is no significant variation for $\mathrm{Cu}$ concentrations in all Eucalyptus samples either polluted samples or control ones.

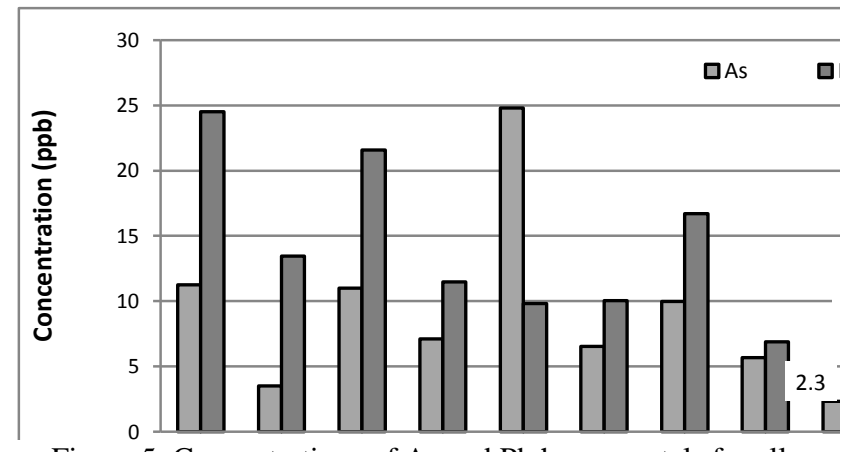

Figure 5. Concentrations of $\mathrm{As}$ and $\mathrm{Pb}$ heavy metals for all Eucalyptus samples

\subsection{Combination of Spectroscopic and Biochemical Results}

Figure 6 represents the ccombination of biochemical and spectroscopic analysis. This comparison proved by increasing the concentrations of heavy metals in all samples, their spectral profiles for the visible and near infrared regions will be changed while compared with the control sample.

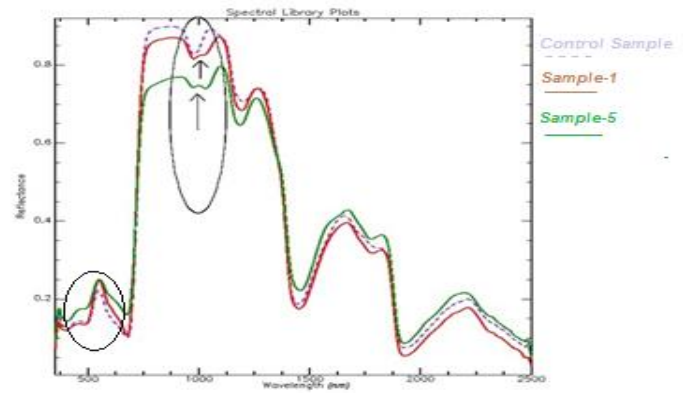

Figure 6. Comparison of spectral profiles for the $1^{\text {st }}$ and $5^{\text {th }}$ and control sample

According to figure 6 and in comparison with control sample, there are some deviations in spectral profile of the $1^{\text {st }}$ and $5^{\text {th }}$ sample throughout the visible and near infrared regions. In this figure also there are two weak reflectance peaks in the range of 940-1120 nm. So, it can be concluded due to high amount of heavy metals in the leaf samples, some variations will be occurred in their spectral profiles. The significant distinction is for the $1^{\text {st }}$ and $4^{\text {th }}$ samples whose $\mathrm{As}$ and $\mathrm{Pb}$ concentrations are relatively higher than the others.

\subsection{Results of Hyperion data analysis}

This section represents the outputs resulted from preprocessing and processing of Hyperion images. It also discusses the findings based on the supporting theory. Finally the way that Hyperion results were employed and compared with those obtained from laboratory and spectroscopic data have been discussed.

\subsubsection{Preprocessing Results of Hyperion images}

\section{a) Separating bad bands}

Before using Hyperion images in this study, about 42 bands were identified to have strong water vapor and identified as the bad bands. So for the subsequent stages of Hyperion analysis They were permanently excluded. 


\section{b) Destripe}

As illustrated in figure $7 \mathrm{a}$, a visual check on the Hyperion images showed that both vertical and horizontal stripes are occurred in some of the bands. To remove these stripes the image was firstly rotated by $80^{\circ}$ clockwise. Therefore, a method suggested by Ede (2004) was employed in order to minimize the vertical striping in pushbroom scanner like Hyperion.

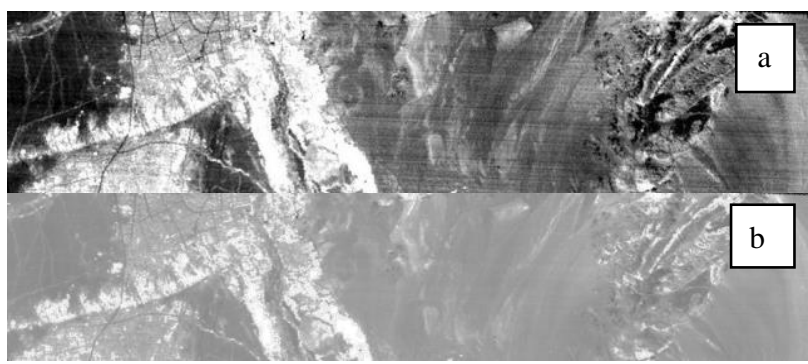

Figure 7. Destriping analysis for Hyperion image: a) before and b) after Striping Removal

Figure 7 shows the Hyperion image of the Bam City before (a) and after (b) destriping analysis. As demonstrated in figure 7b no striping artifacts were observed after removing strips.

\section{c) Atmospheric Correction}

Using FLAASH technique in ENVI, we could minimize the effects of atmosphere, solar illumination, sensor viewing geometry and terrains. Figure 8 illustrates the spectral profile of the selected pixel before (a) and after (b) atmospheric correction.

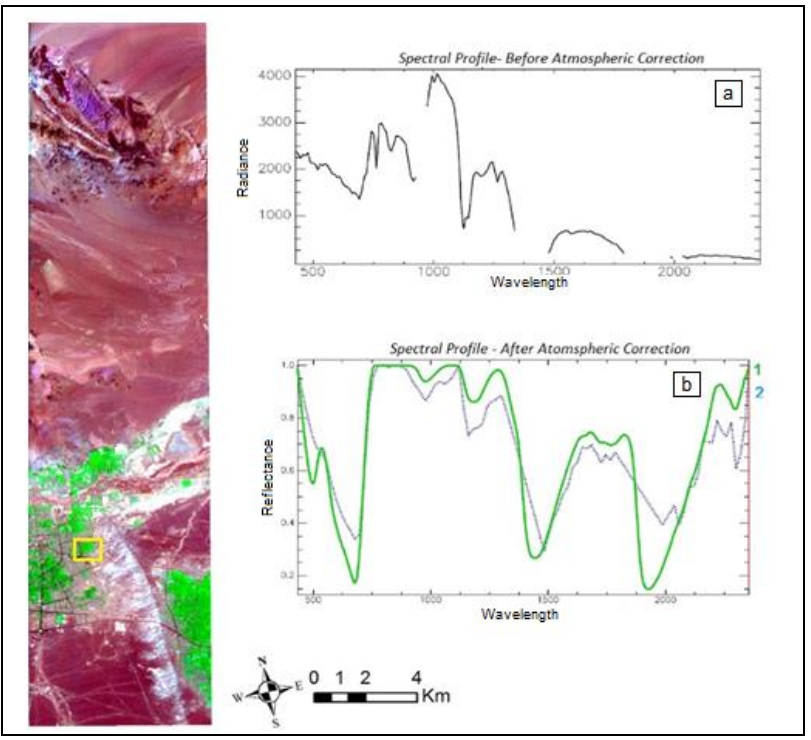

Figure 8. Feature signature before (a) and after (b) atmospheric correction

By minimizing the atmospheric effects in figure 8 , it is expected that the outcome will accurately represent the actual surface reflectance. According to this figure also the spectral profile of the selected feature has changed from radiance unit into reflectance one. It is worth mentioning that the first curve in figure $8 \mathrm{~b}$ is generally related to the reference spectral profile of vegetation and the second one is for Eucalyptus trees which are available in the selected area on this figure.

\section{d) Minimizing noise and dimensionality of data}

Results of MNF transformation for reducing the dimensionality and noise of the data is presented in figure 9. Using this transformation, the data volume was significantly reduced by removing noise-affected band.

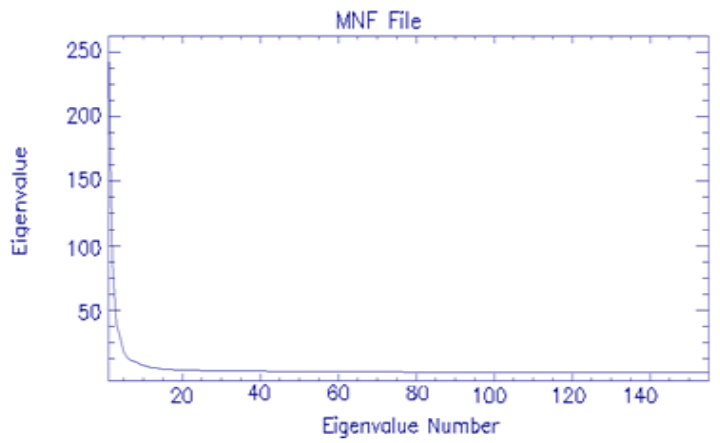

Figure 9. Correlations between eigenvalues and eigenvalue numbers using MNF transformation

According to figure 9 the noise affected band can be identified using eigenvalues plot as well as the eigenimages i.e. MNF band images. This figure also shows that the most coherent data would contained within the first $20 \mathrm{MNF}$ bands, while the rest of the MNF bands would contain noise affected data, made them unsuitable to further stages.

\subsubsection{Processing Results of Hyperion images}

\section{a) Pure Pixels and Endmembers Extraction}

After removing the noise and dimensionality of data, the first 20 coherent MNF bands were used as input for ENVI's Pixel Purity Index (PPI) routine. Figure 10 represents the results of PPI technique which shows both number and distribution of pure pixels in our study area. According to this figure, the number of pure pixels found during the PPI iteration process was 130,000 which obtained after 10,000 iterations.

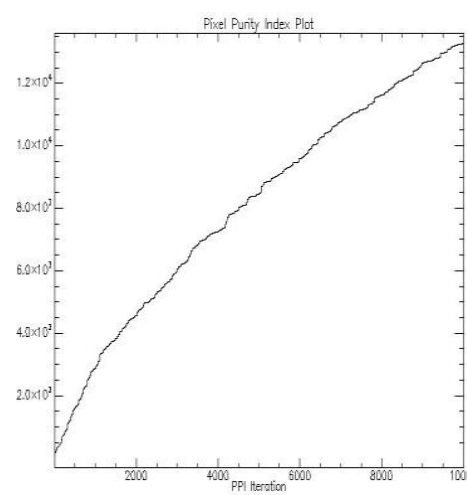

(a)

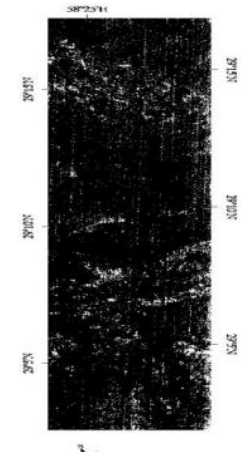

(b)
Figure 10. (a) PPI curve (b) PPI image

After indicating the purest pixels on image, detemination of the endmembers were conducted by n-Dimensional Visualizer in ENVI to interactively select the endmembers in $\mathrm{nD}$ space. However, this method is subject to the analyst experience and knowledge, so careful action need to be taken to minimize the bias from occurring. Finally, this routine extracted 2 endmembers, which referres to the two dominant vegetations in the case study namely, Eucaliptus and Palm trees. 


\section{b) Supervised classification using SAM algorithm}

Since there wasn't any standard spectral signature of contaminated Eucalyptus in our study area, we used the groundbased spectra that were measured by spectrometer device. These spectra were finally inputted to the SAM algorithm for supervised classification.

As previously mentioned, the biochemical analysis of this study proved that Eucaliptus trees have been contaminated by As and $\mathrm{Pb}$. Using ground-based spectra of those samples which contained the high levels of $\mathrm{As}$ and $\mathrm{Pb}$, the $\mathrm{SAM}$ classification was implemented. According to figure 11 the contaminated region by high values of $\mathrm{As}$ and $\mathrm{Pb}$ classified into one category and the other unpolluted areas whose spectral signature were similar to control sample were placed in the other class.

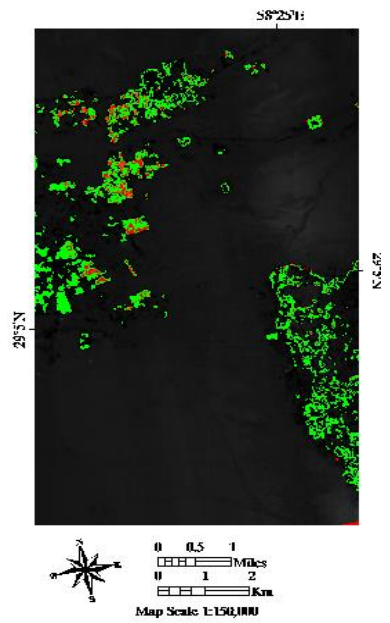

Figure 11. Classification of polluted (red pointes) and unpolluted (green points) regions by SAM algorithm

Figure 11 shows the classified image of the case study by SAM technique. According to this figure the contaminated Eucalyptus trees in the region were specified using red points. So the unpolluted ones namely healthy trees were remained in the green color.

\section{SUMMARY AND CONCLUSIONS}

Paying attention to the environmental contaminations is of great importance due to their impact on the food chains, human health and sustainable developments of ecosystems. In this regards, the identification of heavy metals that could be accumulated by Eucalyptus trees and have located in northern part of Bam City was the main objective of this study. Moreover, combination of biochemical and hyperspectral techniques to specify the spatial distribution of contaminated Eucalyptuses and classify the polluted and unpolluted areas of case study is another task that was fulfilled in this paper.

In this regard, using biochemical approach, the concentration of heavy metals in Eucalyptuses leaf samples was measured though GF-AAS device and the respective values were compared with control samples. In order to make the standard spectral signature of leaf samples, their spectral profiles were measured by ASD spectrometer. These spectra then were employed for classification purposes. For this aim, by employing the SAM classification methods as well as combination of biochemical analysis, spectral measurements of samples and hyperspectral images of EO-1 satellite, the spatial distribution of heavy metals in the region was determined. To achieve this goal, the spectral signature of those samples whose $\mathrm{As}$ and $\mathrm{Pb}$ values were higher than others inputted to the SAM algorithm. The distribution of polluted and unpolluted areas then was carried out by classification methods.

Results showed that Eucalyptus trees accumulates the heavy metals of $\mathrm{As}$ and $\mathrm{Pb}$ with the average concentrations equalling 9.98 and $14.31 \mathrm{ppb}$ while compared with the relevant control samples equalling 2.32 and $8.98 \mathrm{ppb}$, respectively. Combination of biochemical and hyperspectral data analysis also proved that by increasing concentration of $\mathrm{As}$ and $\mathrm{Pb}$, the spectral profiles of all samples for the visible and near infrared regions were changed while compared with control sample. For the $1^{\text {st }}$ and $5^{\text {th }}$ samples containing the high levels of $\mathrm{As}$ and $\mathrm{Pb}$, there were also two weak reflectance peaks in the range of $940-1120 \mathrm{~nm}$. So, it can be concluded due to high amount of heavy metals in the leaf samples, some variations will be occurred in their spectral profiles.

\section{REFERENCES}

Blackburn, G.A., 1998. Spectral indices for estimating photosynthetic pigment concentrations: A test using senescent tree leaves. Int. J. Remote Sens. 19 (4), pp. 657-675.

Conesa, H.M., Fazb, A., Arnaldos, R., 2006. Heavy metal accumulation and tolerance in plants frommine tailings of the semiarid Cartagena-La Unio mining district (SE Spain). Science of the Total Environment, 366 (1), pp. 1-11.

Darmavan, A., 2006. Mapping soil mineral using hyperion imagery in relation to 2-the level of structural damage in the bam earthquake. An Investigative Project Report in Master of Applied Science in GIS Department of Geomatics, Faculty of Engineering, University of Melbourne.

Ede, R. v., 2004. Destriping and Geometric Correction of an ASTER Level 1A Image. Utrecht University, Utrecht.

https://lta.cr.usgs.gov/EO1.html

\section{http://www.epa.gov}

http://www.exelisvis.com/docs/HyperionVegetationAnalysisTut orial.html

Kratt, C., Calvin, W.M., Coolbaugh, M.F., 2010. Mineral mapping in the Pyramid Lakebasin: hydrothermal alteration, chemical precipitates and geothermal energy potential. Remote Sensing of Environment, 114, pp. 2297-2304.

Kruse, F. A., Boardman, J. W., Huntington, J. F., 2002. Comparison of EO-1 Hyperion and Airborne Hyperspectral Remote Sensing Data for Geologic Applications: in Proceedings. SPIE Aerospace Conference, 9-16 March 2002, Big Sky, Montana.

Kurse, F.A., Boardman, J.W., Huntington, J.F. 2003. Comparison of Airborne Hyperspectral Data and EO-1 Hyperion for Mineral Mapping. IEEE transactions on Geoscience and remote sensing, 41, pp. 1388-1400. 
Li, Q., Yang, F., Zhang, B., Zhang, X., Zhou, G., 2008. Biogeochemistry responses and spectral characteristics of Rhus chinensis Mill under heavy metal contamination stress (in Chinese). Journal of Remote Sensing, 12 (2), pp. 284-290.

Lintern, M., Anand, R., Ryan, C., Paterson, D., 2013. Natural gold particles in Eucalyptus leaves and their relevance to exploration for buried gold deposits. Nat. Commun, DOI: $10.1038 /$ ncomms 3614 .

Liu, Y., Chen, H., Wu, G., Wu, X., 2010. Feasibility of estimating heavy metal concentrations in Phragmites Australis using laboratory-based hyperspectral data: A case study along Le'an River, China. International Journal of Applied Earth Observation and Geoinformation, 12, pp. 166-170.

Liu, M.L., Liu, X.N., Li, T., Xiu, L.N., 2010. Analysis of hyperspectral singularity of rice under $\mathrm{Zn}$ pollution stress. Transactions of the CSAE, 26, pp. 191-197.

Liu, M., Liu, X., Ding, W., Wu, L., 2010. Monitoring stress levels on rice with heavy metal pollution from hyperspectral reflectance data using wavelet-fractal analysis. International Journal of Applied Earth Observation and Geoinformation, 13 pp. 246-255.

Mutanga, O., Skidmore, A.K., 2004b. Integrating imaging spectroscopy and neural networks to map grass quality in the Kruger National Park, South Africa. Remote Sensing of Environment 90 (1), 104-115.

Mutanga, O., Skidmore, A.K., 2007. Red edge shift and biochemical content in grass canopies. Journal of Photogrammetry and Remote Sensing, 62 (1), pp. 34-42.

Pugh, R.E., Dick, D.G., Fredeen, A.L., 2002. Heavy metal (Pb, $\mathrm{Zn}, \mathrm{Cd}, \mathrm{Fe}$, and $\mathrm{Cu}$ ) contents of plant foliage near the Anvil Range Lead/Zinc Mine, Faro, Yukon Territory. Ecotoxicology and Environmental Safety, 52(3), pp. 273-279.

Rashmi, S., Swapna, A.,Venkat, Ravikiran, S., 2014. Spectral Angle Mapper Algorithm for Remote Sensing Image Classification, 1(4), pp. 201-205.

Research Systems Inc. 2005. ENVI Online Help. Boulder, Colorado: Research Systems Inc.

Rosso, P.H., Pushnik, J.C., Lay, M., Ustin, S.L., 2005. Reflectance properties and physiological responses of Salicornia virginica to heavy metal and petroleum contamination. Environmental Pollution, 137 (2), pp. 241-252.

Shakya, K., Chettri, M., Sawidis, T., 2008. Impact of heavy metals (copper, zinc, and lead) on the chlorophyll content of some mosses. Archives of Environmental Contamination and Toxicology, 54 (3), pp. 412-421.

Stephen, G. U., Pearlman, J. S., Mendenhall, J. A., Reuter, D., 2003. Overview of the Earth Observing One (EO-1) Mission, IEEE, 41, pp. 1148-1159. 